Special Issue of the 6th International Congress \& Exhibition (APMAS2016), Maslak, Istanbul, Turkey, June 1-3, 2016

\title{
Evaluation of Friction Coefficient and Adhesion Properties of Silicon Carbon Nitride Films Prepared by HWCVD
}

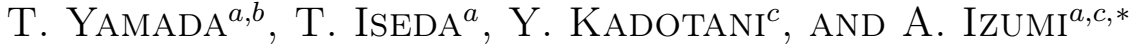 \\ ${ }^{a}$ Kyushu Institute of Technology, 1-1 Sensui, Tobata, Kitakyushu, Fukuoka 804-8550, Japan \\ ${ }^{b}$ Polytechnic College Fukuyama, 4-8-48 Kitahonjyou, Fukuyama, 720-0074, Japan \\ ${ }^{c}$ Top Macoat Co., Ltd. 6-31-1 Mizuki, Dazaifu, Fukuoka 818-0131, Japan
}

\begin{abstract}
We have investigated the friction-coefficient properties of silicon carbon nitride ( $\mathrm{SiCN})$ films deposited on stainless steel substrates and the adhesion properties of SiCN films deposited on $\mathrm{Si}(100)$. The SiCN films were deposited by hot-wire chemical vapor deposition using hexamethyldisilazane and ammonium. It was found that SiCN coating was able to effectively reduce the frictional coefficient of the stainless steel substrates. The adhesion strength was measured by surface-interface physical property analysis equipment (SAICAS) and was found to be $45 \mathrm{~N} / \mathrm{m}$ for the as-deposited $\mathrm{SiCN}$ film on $\mathrm{Si}(100)$. Furthermore, a maximum adhesive strength of $92 \mathrm{~N} / \mathrm{m}$ was obtained after treating the film for $10 \mathrm{~min}$ at $1000^{\circ} \mathrm{C}$.
\end{abstract}

DOI: 10.12693/APhysPolA.131.463

PACS/topics: SiCN, HWCVD, friction-coefficient, adhesion strength

\section{Introduction}

Surface coating is crucial for improving the performance and prolonging the lifetime of metal products, such as molds and cutting tools. Diamond-like carbon (DLC) is a promising candidate for use as coating material. DLC is a metastable amorphous carbon with excellent tribological and mechanical properties [1] that make it well suited for the hot embossing process. However, high internal stress, poor adhesion to substrates, and limited coating thickness have prevented the use of DLC in certain applications $[2,3]$. In addition, the beginning of graphitization (i.e., $\mathrm{sp}^{3}$ to $\mathrm{sp}^{2}$ transformation) at high temperatures [4] renders DLC unsuitable for coating molds under elevated temperature conditions. We believe that silicon carbon nitride ( $\mathrm{SiCN})$ films offer a solution to these problems. SiCN films are transparent, insulating, and have high hardness, frictional tolerance, as well as weather resistance. Hot-wire chemical vapor deposition (HWCVD), sometimes referred to as Cat-CVD, has attracted attention as a possible alternative to plasmaenhanced CVD for low-temperature film deposition [5-7]. Moreover, $\mathrm{SiH}_{4}$ is typically required for the deposition of SiCN films, but general industries are not allowed to use $\mathrm{SiH}_{4}$ owing to its volatile and poisonous nature. To avoid these safety issues, we have previously deposited SiCN films by HWCVD, using non-explosive organic liquid hexamethyldisilazane (HMDS) [8], which has allowed the use of SiCN films by general industries.

We will determine whether SiCN can be applied as a coating film for metal products, especially for molds. As an introductory study, we have investigated the friction-coefficient properties of SiCN films deposited on

\footnotetext{
*corresponding author; e-mail: izumi@ele.kyutech.ac.jp
}

stainless steel (SUS) substrates and the adhesion properties of $\mathrm{SiCN}$ films deposited on $\mathrm{Si}(100)$. We have also investigated the adhesion properties of post-heat-treated SiCN films on $\mathrm{Si}(100)$.

\section{Experimental}

Figure 1 shows the schematic cross-section of the HWCVD apparatus. Prior to deposition $\mathrm{Si}(100)$ substrates were treated in HF solution. Then, $\mathrm{Si}(100)$ and/or mirror-polished SUS 304 substrates were placed in a vacuum chamber maintained at a pressure of $1.5 \times 10^{-4} \mathrm{~Pa}$, and an $\mathrm{NH}_{3}$ radical treatment was performed for $10 \mathrm{~min}$. HMDS was subsequently supplied to the chamber and a SiCN film was deposited under the typical deposition conditions shown in Table I. We have placed a $0.5 \mathrm{~mm}$ diameter zigzag-shaped tungsten (W) filament below the substrate. This filament and the substrate were maintained at temperatures of $1600^{\circ} \mathrm{C}$ and $250{ }^{\circ} \mathrm{C}$, respectively. HMDS and $\mathrm{NH}_{3}$ become active radicals by the catalytic cracking reaction on the heated $\mathrm{W}$ wire, similar to other kind of films growth, which are using HWCVD [9]. Then the produced radicals react on the substrate and contri-

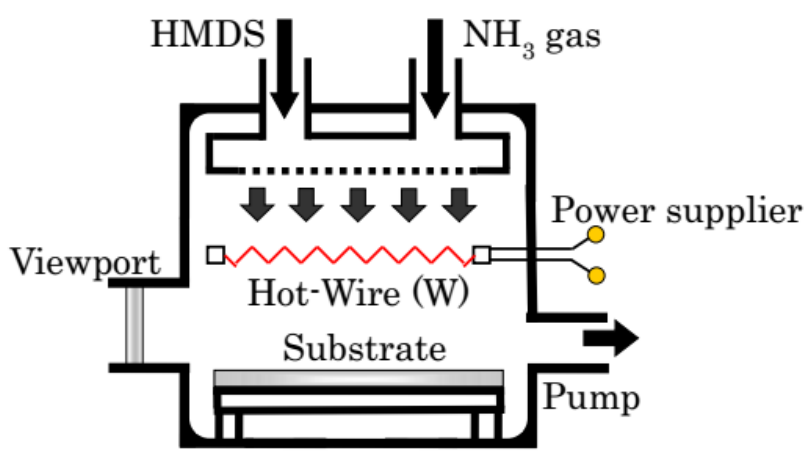

Fig. 1. Schematic diagram of the HWCVD. 
bute to growth of SiCN films on the substrate. The substrate temperature was monitored using a thermocouple attached to the substrate holder. In addition, the film thickness and refractive index were measured by ellipsometry using a $632.8 \mathrm{~nm}$ wavelength $\mathrm{He}-\mathrm{Ne}$ laser.

TABLE I

Exprimental conditions.

\begin{tabular}{c|c}
\hline \hline Substrates & $\mathrm{Si}(100)$, SUS304 \\
\hline Catalyst material & Tungsten $(\mathrm{W})$ \\
\hline Back pressure $[\mathrm{Pa}]$ & $1.5 \times 10^{-4}$ \\
\hline Catalyzer temperature $\left[{ }^{\circ} \mathrm{C}\right]$ & 1600 \\
\hline $\mathrm{NH}_{3}$ gas flow rate $[\mathrm{sccm}]$ & 50 \\
\hline $\mathrm{NH}_{3}$ treatment $[\mathrm{min}]$ & 10 \\
\hline Gas pressure $[\mathrm{Pa}]$ & 1.2 \\
\hline HMDS gas flow rate $[\mathrm{sccm}]$ & 1.3
\end{tabular}

The friction coefficient of the SiCN film deposited on SUS 304 was measured using an apparatus in accordance with the Japanese Industrial Standard (JIS) K 7125. The measurement set-up is shown in Fig. 2. The measurement conditions were as follows, loading weight of $5 \mathrm{kN}$ and test speeds of $10 \mathrm{~mm} / \mathrm{min}, 50 \mathrm{~mm} / \mathrm{min}$, and $100 \mathrm{~mm} / \mathrm{min}$. The contact area of the sample was $100 \times 100 \mathrm{~mm}^{2}$. A mirror-polished SUS 304 substrate was coated with a $\mathrm{SiCN}$ film with a thickness of about $280 \mathrm{~nm}$.

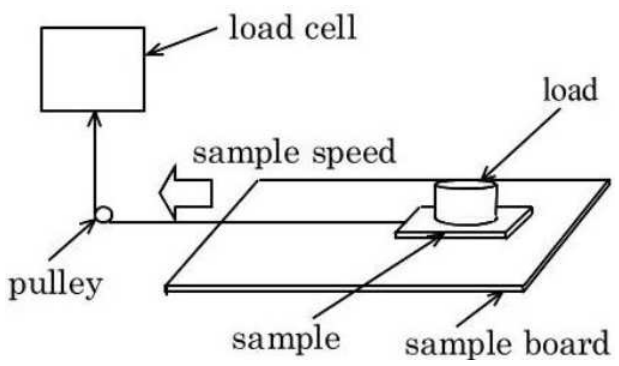

Fig. 2. Schematic diagram of the friction coefficient set-up, in accordance with the Japanese Industrial Standard (JIS) K 7125

The adhesion strength and film structure of a SiCN film with a thickness of about $100 \mathrm{~nm}$ deposited on $\mathrm{Si}(100)$ were measured by surface-interface physical property analysis equipment (DAIPLA WINTES Corp., SAICAS BN-1) [10, 11] and determined using Fourier transform infrared (FTIR) spectroscopy, respectively.

Furthermore, the films deposited on $\mathrm{Si}(100)$ were heattreated for $10 \mathrm{~min}$ in nitrogen $\left(\mathrm{N}_{2}\right)$ at temperatures ranging from $400{ }^{\circ} \mathrm{C}$ to $1000^{\circ} \mathrm{C}$. Heat treatments in nitrogen were also performed at a fixed temperature of $1000^{\circ} \mathrm{C}$ for periods of time ranging from 10 to $240 \mathrm{~min}$.

\section{Results and discussion}

Figure 3 shows the relation between the frictional force and the sliding distance for the SUS 304 substrates with and without SiCN film deposition. It is found that the frictional force is drastically reduced for the sample with the SiCN coating, compared to the uncoated sample.

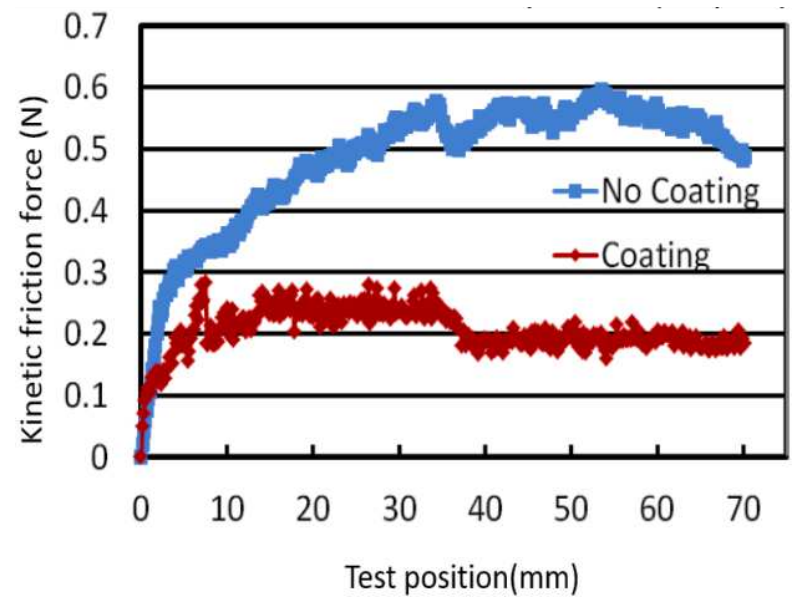

Fig. 3. Frictional force vs. sliding distance for the SUS 304 substrates with and without SiCN film deposition.

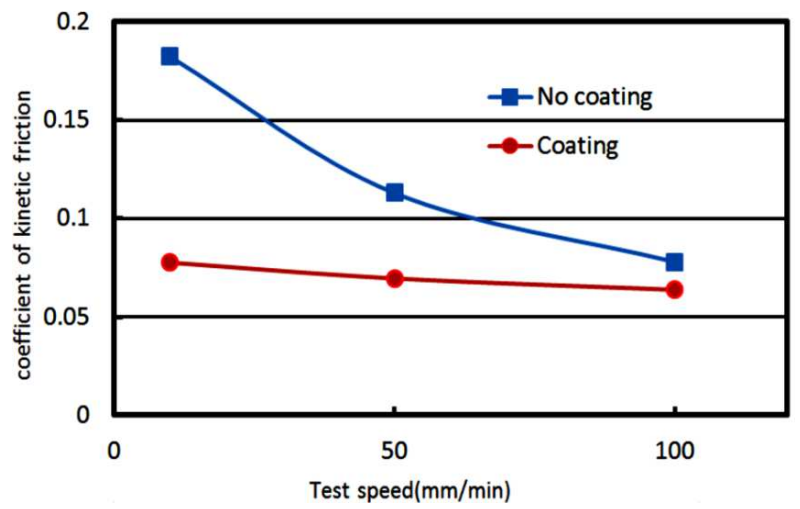

Fig. 4. Dynamic friction coefficient vs. sample velocity.

Figure 4 depicts the relationship between the dynamic friction coefficient and sample velocity. The coefficient of dynamic friction was calculated by dividing the mean value of the frictional force by the load at the slip distance of $10 \mathrm{~mm}$ or more, and the sliding distance of $60 \mathrm{~mm}$. It was revealed that the change in the dynamic friction coefficient of the SiCN-coated sample is smaller than that of the uncoated sample. It was also found that the dynamic friction coefficient is reduced when the test speed is higher.

It is concluded that SiCN coating is able to effectively reduce the frictional coefficient of the SUS substrate.

Figure 5 shows the composition ratios of the SiCN films on $\mathrm{Si}(100)$, obtained by FTIR spectroscopy. Heat treatment resulted in a decrease in the fraction of $\mathrm{Si}-\mathrm{C}$ bonds from $\sim 60 \%$ in the as-deposited film to $\sim 20 \%$ after heating at $1000^{\circ} \mathrm{C}$. Additionally, the fraction of Si-O bonds has increased with the heat treatment and has saturated above $700^{\circ} \mathrm{C}$. The SiCN surface is believed to be oxidized by the heat treatment. 


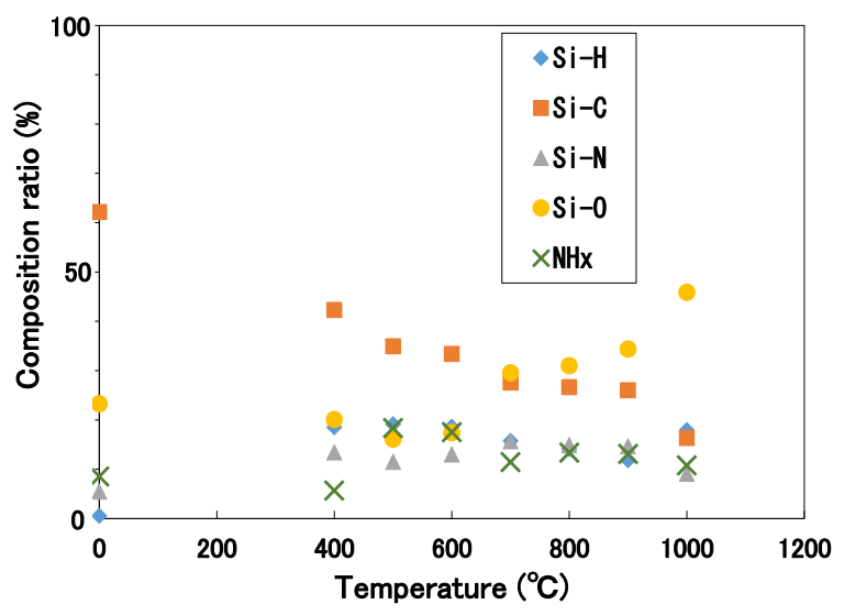

Fig. 5. Composition ratio of $\mathrm{SiCN}$ vs. heat treatment temperature (treatment time was fixed at $10 \mathrm{~min}$ ).

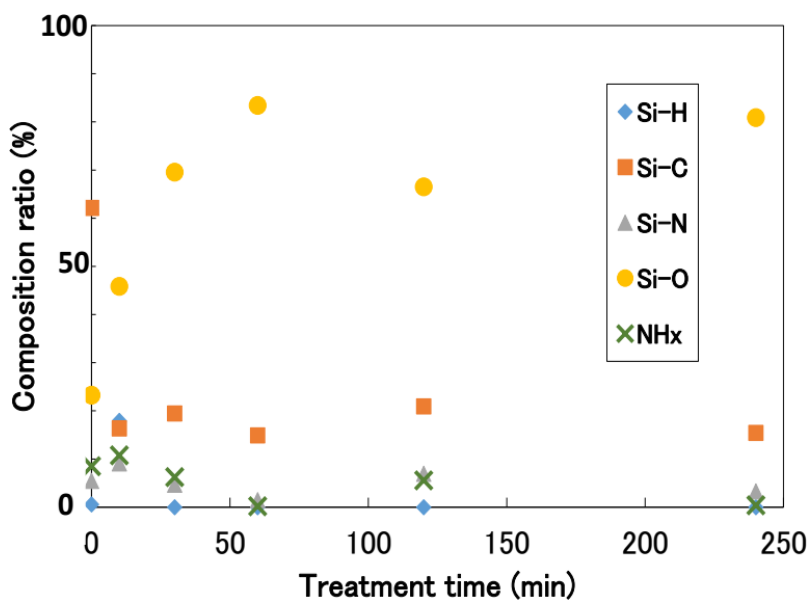

Fig. 6. Composition ratio of $\mathrm{SiCN}$ vs. heat treatment time (temperature was fixed at $1000^{\circ} \mathrm{C}$ ).

Figure 6 shows the relation between the composition ratio of $\mathrm{SiCN}$ and heat-treatment time. The temperature was fixed at $1000^{\circ} \mathrm{C}$. It was revealed that $\mathrm{Si}-\mathrm{C}$ and $\mathrm{Si}-\mathrm{O}$ bond ratios decrease and increase from 23 to $\sim 80 \%$, respectively, with increasing heating time. The fraction of $\mathrm{Si}-\mathrm{O}$ bonds has saturated after $60 \mathrm{~min}$, indicating that the oxidization limit of the SiCN film surface had been reached.

Figure 7 shows the relation between the adhesion force of $\mathrm{SiCN} / \mathrm{Si}(100)$ and heat-treatment temperature. The treatment temperature was fixed at $10 \mathrm{~min}$. It was found that the adhesion strength increases, in general, with increasing heat-treatment temperature. For example, the adhesion strength has increased from $45 \mathrm{~N} / \mathrm{m}$ in the nonheat-treated sample and saturated at $\sim 93 \mathrm{~N} / \mathrm{m}$ after heat treatment at temperatures of $800^{\circ} \mathrm{C}$ and higher.

Figure 8 shows the relation between the adhesion force of $\mathrm{SiCN} / \mathrm{Si}(100)$ and heat-treatment time. The temperature was fixed at $1000^{\circ} \mathrm{C}$. It was found that the adhesion strength increases from 49 to $90 \mathrm{~N} / \mathrm{m}$ for heat-treatment time of up to $10 \mathrm{~min}$, and decreases thereafter.

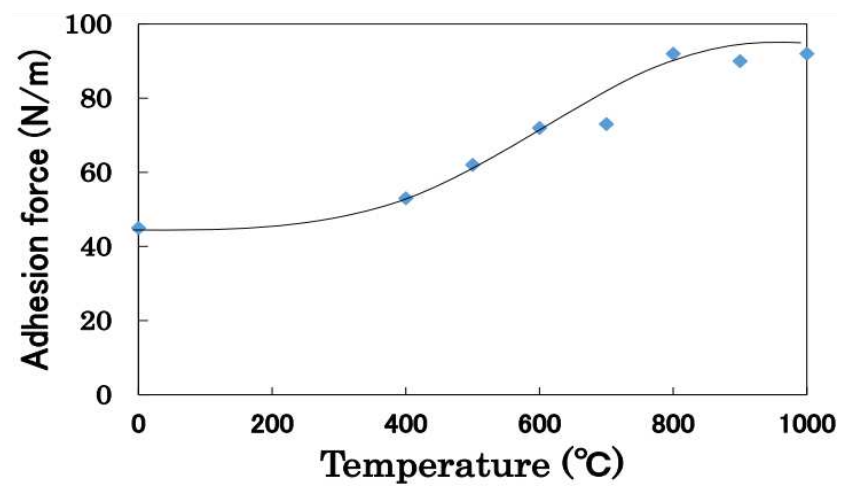

Fig. 7. Adhesion force of $\mathrm{SiCN} / \mathrm{Si}(100)$ vs. heat treatment temperature (treatment time was fixed at $10 \mathrm{~min}$ ).

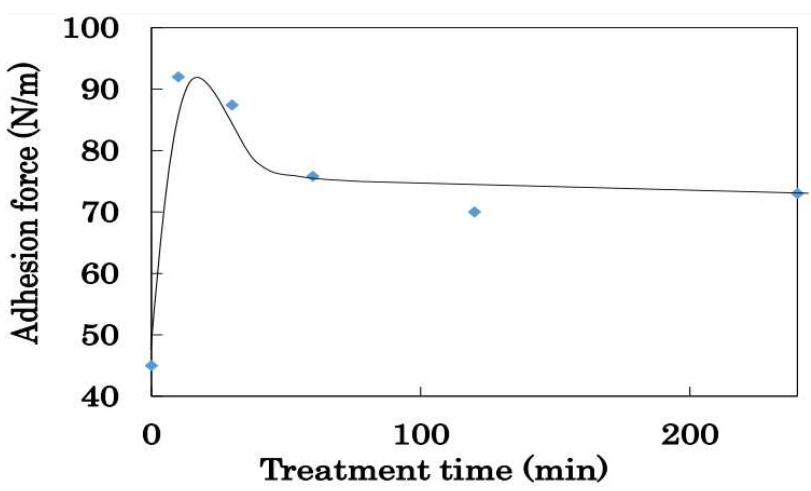

Fig. 8. Adhesion force of $\mathrm{SiCN} / \mathrm{Si}(100)$ vs. heat treatment time (temperature was fixed at $1000^{\circ} \mathrm{C}$ ).

The adhesion strength of a $200 \mathrm{~nm}$ thermal $\mathrm{SiO}_{2}$ film deposited on a $\mathrm{Si}(100)$ substrate was measured by SAICAS and found to be $49 \mathrm{~N} / \mathrm{m}$. Therefore, the adhesion strength of SiCN deposited on $\mathrm{Si}(100)$ by HWCVD is much higher than that of thermal $\mathrm{SiO}_{2}$. The adhesion strength increases with heat treatment, which possibly stems from an improvement in the film density and increased fraction of $\mathrm{Si}-\mathrm{O}$ bonds. However, at heat-treatment temperatures above $800^{\circ} \mathrm{C}$, the adhesion strength did not increase significantly with the increasing number of $\mathrm{Si}-\mathrm{O}$ bonds. Therefore, it is believed that increasing fractions of $\mathrm{Si}-\mathrm{O}$ bonds does not influence the adhesion strength. Detailed investigations of the density and bonding states of the SiCN films are necessary to identify the mechanism that leads to increased adhesion strength with heat treatment.

\section{Conclusions}

In this work we have investigated the frictioncoefficient properties of SiCN films deposited on SUS substrates, and the adhesion properties of SiCN films deposited on $\mathrm{Si}(100)$ by HWCVD. It was found that the SiCN coating was able to effectively reduce the frictional coefficient of the SUS substrates. The adhesion strength was measured by SAICAS and found to be $45 \mathrm{~N} / \mathrm{m}$ for the as-deposited SiCN film. Furthermore, a maximum adhesive strength of $92 \mathrm{~N} / \mathrm{m}$ was obtained after heat-treating the film for $10 \mathrm{~min}$ at $1000^{\circ} \mathrm{C}$. 


\section{References}

[1] J. Robertson, Mater. Sci. Eng. R. 37, 129 (2002).

[2] Y. Oka, M. Kirinuki, Y. Nishimura, K. Azuma, E. Fujiwara, M. Yatsuzuka, Surf. Coat. Technol. 186, 141 (2004).

[3] L.F. Bonetti, G. Capote, L.V. Santos, E.J. Corat, V.J. Trava-Airoldi, Thin Solid Films 515, 375 (2006).

[4] J. Vetter, Surf. Coat. Tech. 257, 213 (2014).

[5] S. Yamazaki, Jpn. J. Appl. Phys. 9, 1467 (1970).

[6] H. Wiesmann, A.K. Gosh, T. NcMahon, M. Strongin, J. Appl. Phys. 50, 3752 (1979).
[7] H. Matsumura, Jpn. J. Appl. Phys. 25, L949 (1986).

[8] A. Izumi, K. Oda, Thin Solid Films 501, 195 (2006).

[9] S.G. Ansari, H. Umemoto, T. Morimoto, K. Yoneyama, A. Izumi, A. Masuda, H. Matsumura, Thin Solid Films 501, 31 (2006).

[10] F. Saito, I. Nishiyama, T. Hyodo, Mater. Lett. 63, 2257 (2009).

[11] N. Nagai, I. Nishiyama, Y. Kishima, K. Iida, K. Mori, Appl. Spectrosc. 67, 420 (2013). 